\title{
Universiteit
}

Leiden

The Netherlands

\section{The influence of cognitive emotion regulation strategies and depression severity on deliberate self-harm.}

Slee, N.; Garnefski, N.; Spinhoven, P.; Arensman, E.

\section{Citation}

Slee, N., Garnefski, N., Spinhoven, P., \& Arensman, E. (2008). The influence of cognitive emotion regulation strategies and depression severity on deliberate self-harm. Suicide And Life-Threatening Behavior, 38, 274-286. doi:10.1521/suli.2008.38.3.274

Version: $\quad$ Not Applicable (or Unknown)

License: $\quad$ Leiden University Non-exclusive license

Downloaded from: https://hdl.handle.net/1887/14235

Note: To cite this publication please use the final published version (if applicable). 


\title{
The Influence of Cognitive Emotion Regulation Strategies and Depression Severity on Deliberate Self-Harm
}

\author{
Nadja Slee, PhD, Nadia Garnefski, PhD, Philip Spinhoven, PhD, \\ and Ella Arensman, $\mathrm{PhD}$
}

Elaborating on previous studies on emotion regulation and deliberate selfharm (DSH), in the present study we distinguish between strategies of cognitive content (e.g., suicidal cognitions of perceived burdensomeness, helplessness, poor distress tolerance) and cognitive process (e.g., nonacceptance of emotional responses, lack of awareness of emotional responses). Young women who harmed themselves $(n=85)$ were compared with young women without a history of DSH $(n=93)$ across a broad range of strategies. Significant group differences were found for all measures, even when depression severity was controlled for. In addition, logistic regression analyses showed that both cognitive content strategies and cognitive process strategies made significant independent contributions to the prediction of group membership. Controlling for depression severity, suicidal cognitions, and nonacceptance of emotional responses independently predicted DSH. The strong association between suicidal cognitions and DSH seems to indicate the important role of these cognitions in recurrent and chronic DSH. The strong association between nonacceptance of emotional responses and DSH underscores the notion that DSH can be a way to avoid emotional problems. These findings are discussed in relation to recent cognitive-behavioral interventions and specific therapeutic techniques to further insight into how these interventions might work.

Deliberate self-harm (DSH) mainly occurs in the context of depressed mood or heightened arousal. In this context the person's mind is thought to rapidly become dominated by suicidal thinking, which increases the risk of DSH (Williams, Duggan, Crane, \& Fennell, 2006). This seems to be especially true for

Nadja Slee and Nadia Garnefski are with the Department of Clinical and Health Psychology, Leiden University, The Netherlands; Philip SPInhoven is with the Department of Clinical and Health Psychology and the Department of Psychiatry, Leiden University; and Ella Arensman is with the National Suicide Research Foundation, Cork, Ireland.

We would like to thank all participants of this study. We are also grateful to The Nether- individuals with a long history of DSH. In these individuals, an episode of DSH is often triggered internally (Rudd, 2004); it might have been a fleeting thought or image that triggered the episode. Helping a person to understand and monitor the process of internal triggering seems to be essential to deal effectively with future crises.

lands Organisation for Health Research and Development (ZonMw) for the grant that enabled us to study deliberate self-harm. Contract grant number: 2100.0068

Address correspondence to Nadja Slee, Department of Clinical and Health Psychology, Wassenaarseweg 52, P.O. Box 9555, 2300 RB Leiden, The Netherlands; E-mail: nadja.slee@ planet.nl 
Different therapeutic techniques can be used to help patients to get a better understanding of this process. In traditional cognitive behavior therapy, cognitions are considered to be the central pathway to DSH. Hence, patients learn to identify and restructure specific suicidal thoughts (Rudd, Joiner, \& Rajab, 2001), distorted thinking (e.g., overgeneralized and dichotomous interpretations), and irrational negative beliefs or schemas about themselves and the world (Alford \& Beck, 1997; Young, Klosko, \& Weishaar, 2003). In more recent cognitive-behavioral approaches, such as dialectical behavior therapy, mindfulness-based cognitive therapy, and acceptance and commitment therapy, patients learn to become aware of their thoughts and feelings, noticing the effects of negative thinking on the body and to explore this directly, rather then ruminating about or suppressing negative thoughts and feelings. Through this attitude of mindfulness and acceptance, patients are thought to become less avoidant and reactive to their thoughts and feelings, which may prevent repeated episodes of DSH (Hayes, Follette, \& Linehan, 2004; Hayes, Strosahl, \& Wilson, 1999; Linehan, 1993a,b; Williams, Crane, Barnhofer, Van der Does, \& Segal, 2006). So, both traditional and modern cognitive-behavioral therapies seem to agree about the central role of cognitions in DSH. These therapies all look for ways to help patients to regulate their emotions through thoughts. In line with the distinction between more traditional and more recent cognitive-behavioral therapies, a distinction can be made between cognitive content and cognitive processes in DSH.

First, cognitive content refers to thoughts and appraisals available to introspection and for self-report (Kendall \& Ingram, 1989). Individuals who engage in DSH often report cognitions of hopelessness (e.g., Glanz, Haas, \& Sweeney, 1995; McGee, Williams, \& Nada-Raja, 2001), helplessness (Bancroft et al., 1979; D'Zurilla, Chang, Nottingham, \& Faccini, 1998), of being a burden to loved ones (Brown \& Vinokur, 2003; Joiner, Rudd, \& Lester, 2002), low selfesteem (McGee et al., 2001; Grøholt, Eke- berg, Wichstrøm, \& Haldorsen, 2005), selfcriticism and self-blame (Donaldson, Spirito, \& Farnett, 2000; Fazaa \& Page, 2003; Garnefski, Kraaij, \& Spinhoven, 2001b), catastrophizing (Garnefski et al., 2001b), and perfectionism (Donaldson et al., 2000). It has been argued that when mood deteriorates, the mind of DSH patients becomes dominated by suicidal cognitions of unlovability, helplessness, poor distress tolerance, and perceived burdensomeness: "I am completely unworthy of love," "Nobody can help me to solve my problems," "I can't stand this pain anymore," "I do not deserve to live" (Rudd et al., 2001; Williams, Crane, Barnhoffer, et al., 2006). These cognitions might attenuate the motivation to inhibit the urge to engage in DSH (Rudd et al., 2001).

Second, with regard to cognitive processes, several aspects can be distinguished, such as the extent to which emotions are tolerated or accepted (Gratz \& Roemer, 2004), the extent to which people are aware of their emotions (Gratz \& Roemer, 2004), and the extent to which they engage in rumination (Garnefski, Teerds, Kraaij, Legerstee, \& van den Kommer, 2004; Watkins \& Teasdale, 2004). Preliminary findings suggest that lack of awareness of emotions and nonacceptance of emotions have predictive value for repeated DSH (Gratz \& Roemer, 2004). Furthermore, rumination exacerbates depression (Nolen-Hoeksema, 1991); increases the likelihood, severity, and duration of depression (Nolen-Hoeksema, 2002); and has been found to mediate the relationship between cognitive vulnerability and suicidal ideation (Smith, Alloy, \& Abramson, 2006). However, a mindful, nonjudgemental attitude toward depression-related emotions, cognitions, and bodily sensations is thought to prevent escalation of negative thoughts into suicidal thinking and repetition of DSH (Williams et al., 2006). Wells and Matthews (1994) describe a similar cognitive process called "detached mindfulness." This type of processing is expected to facilitate the development of a metacognitive mode, in which thoughts are not seen as realities, but as mental events (Wells, 2002). 
The primary objective of the present study was to investigate the relationship between the use of different cognitive emotion regulation strategies ${ }^{1}$ and DSH in young women. More specifically, the cognitive content strategies and the cognitive process strategies used in a group of young women who engage in DSH were compared to those of young women without a history of DSH. The first goal was to focus on the extent to which group differences existed on these strategies. It was hypothesized that members of the clinical group would report higher scores on suicidal cognitions (helplessness, perceived burdensomeness, poor distress tolerance, unlovability), self-blame, catastrophizing, lack of awareness of emotions, and nonacceptance of emotions, as most of the previous research showed relationships of these aspects with DSH (Donaldson et al., 2000; Garnefski et al., 2001b; Gratz \& Roemer, 2004; Joiner et al., 2002; Rudd et al., 2001). It was also expected that those who had not engaged in DSH would have higher scores on measures for positive self-concept and positive reappraisal, as most of the previous research had shown positive relationships of these strategies with a positive mood (Garnefski et al., 2001a; Grøholt et al., 2005; McGee et al., 2001). The differences were expected to hold when depression severity was controlled for.

The secondary objective was to examine which of the cognitive emotion regulation strategies were relatively best able to distinguish between the groups. We studied the unique contribution of both cognitive content and cognitive process strategies in predicting DSH. It was expected that these cognitive strategies would account for a considerable amount of the variance and that suicidal cognitions, self-blame, and difficulties with emotion regulation (e.g., nonacceptance of emotions, lack of clarity of emotions, difficulty controlling impulses when emotional) would

1. The use of the term strategies does not imply an instrumental or motivational function of beliefs. be significantly related to clinical group membership, while a positive self-concept and positive reappraisal would be significantly related to the group without a history of DSH (Donaldson et al., 2000; Garnefski et al., 2001b; Grøholt et al., 2005; McGee et al., 2001). While looking for the strongest cognitive predictors of DSH we also controlled for depression severity, since these cognitions may fluctuate with negative mood but they may also represent a more trait-like vulnerability component consistent over time. By disentangling the influence of cognitions and depression, we hoped to gain a better understanding of the unique influence of cognitive emotion regulation on DSH, independent from and above the influence of depression severity.

\section{METHODS}

\section{Clinical Group}

The present study is part of a larger study among 100 young people (age 15-35, $89 \%$ female) who had been referred to the Leiden University Medical Centre or the mental health care centre in Leiden following an episode of DSH (Slee, Garnefski, van der Leeden, Arensman, \& Spinhoven, 2007). DSH was defined as including both deliberate self-poisoning (overdose) and deliberate self-injury (Hawton, Zahl, \& Weatherall, 2003), regardless of intent to die. Consent for participation was obtained from all participants and from parents of adolescents below the age of 16 years. Participants were interviewed in their home or at the local hospital within 2 weeks of the index episode. The present study focused on young women with DSH because a previous study in Leiden had shown that the average rate of DSH among area females aged 15-24 was quite high with 179 per 100,000 (Arensman, Kerkhof, Hengeveld, \& Mulder, 1995). For the purpose of the present study, individuals were excluded if they were male $(n=10)$, decided not to participate $(n=2)$, were unable to converse in Dutch $(n=2)$, or were cogni- 
tively impaired $(n=1)$, which brings the total number of women included in the study to 85 (mean age $=24.0, S D=5.6$ ). Most women had a long history of DSH. Two thirds reported 10 or more previous episodes of DSH. The study had the approval of the ethics committee of the Leiden University Medical Centre.

\section{Comparison Group of Females Without a History of DSH}

The study was carried out in different schools for higher vocational training by means of a 45-minute written questionnaire that 123 female students filled out during school hours, under supervision of a graduate psychology student and a teacher. The students were guaranteed anonymity in relation to their parents, teachers, and fellow students. Consent for participation was obtained from all the participants and from parents of adolescents below the age of 16 years. Twenty-two percent $(n=27)$ reported to have engaged in DSH in the past. These students were excluded from the study. Three more students decided not to participate, which brings the total number of students included in the study to 93 (mean age $=23.3$, $S D=8.3)$.

\section{Assessment Measures}

For both groups demographic information was obtained. Any previous acts of DSH were also recorded. The participants completed a depression scale and several measures of cognitive content and cognitive process.

\section{Measure of Depression Severity}

The Beck Depression Inventory II (BDI-II; Beck, Steer, \& Brown, 1996), a 21item depression scale with each answer rated $0-3$, was used to measure depression severity. Scores range from 0 to 63 . The BDI-II has high internal consistency with an alpha reliability of .91 (Beck et al., 1996; Beck, Steer,
Ball, \& Ranieri, 1996). In this study we found an alpha of .93 for the clinical group and an alpha of .80 for the comparison group.

\section{Measures of Cognitive Content}

Suicide Cognition Scale (Rudd et al., 2001). Participants were asked 20 questions about core beliefs of perceived burdensomeness (e.g., "I am a burden to my family"), helplessness (e.g., "No one can help solve my problems"), unlovablity (e.g., "I am completely unworthy of love"), and poor distress tolerance (e.g., "When I get this upset, it is unbearable"), with each answer rated 1 (strongly disagree) to 5 (strongly agree). Scores range from 20 to 100 . No data have been published yet on the internal consistency of the scale. In the clinical group we found alpha reliabilities of .65 (perceived burdensomeness), .88 (helplessness), .88 (unlovability), and .90 (poor distress tolerance). The alpha reliability for the total scale was .95. In the comparison group we found alphas of .67 (perceived burdensomeness), .79 (helplessness), .87 (unlovability), and .83 (poor distress tolerance). The alpha reliability for the total scale was .93. Even the lowest value of .65 for perceived burdensomeness is still acceptable when the number of items (2) is considered.

Robson Self-Concept Questionnaire, Short version (Robson, 1989). This 8 -item questionnaire deals with attitudes and beliefs that people have about themselves ("I'm glad I am who I am"). All items are self-rated from 1-4 (strongly disagree to strongly agree). Scores range from 8 to 32 . The scale has good validity and reliability (Robson, 1989). In the clinical group we found an alpha of .81. In the comparison group we found an alpha of .77.

Cognitive Emotion Regulation Questionnaire (CERQ; Garnefski, Kraaij, \& Spinhoven, 2002). This 36-question instrument is used to assess what people tend to think after the experience of stressful life events. Items are scored on a Likert-scale ranging from 1 (almost never) to 5 (almost always). The instrument includes nine scales. Based on previous 
research from Garnefski et al. (2001b), three subscales were selected: self-blame (e.g., "I feel that I am the one to blame for it"), positive reappraisal (e.g., "I think that the situation also has its positive sides"), and catastrophizing (e.g., "I often think that what I have experienced is the worst that can happen to a person"). Scores on the subscales range from 4 to 20. Research has shown that all subscales have good internal consistencies (Garnefski et al., 2002). In a patient sample alpha reliabilities of .72 to .85 were found. In a late adolescent sample alpha reliabilities of .68 to .79 were found. In the clinical group we found alpha reliabilities of .73 to .92 . In the comparison group we found alphas of .74 to .81 .

\section{Measure of Cognitive Process}

Difficulties in Emotion Regulation Questionnaire (DERS; Gratz \& Roemer, 2004). The DERS included 36 questions about difficulties in emotion regulation. It contains six dimensions of emotion regulation wherein difficulties may occur, including (1) lack of awareness of emotional responses (e.g., "I pay attention to how I feel" = reverse-scored item), (2) lack of clarity of emotional responses (e.g., "I have difficulty making sense out of my feelings"), (3) nonacceptance of emotional responses (e.g., "When I'm upset, I feel ashamed with myself for feeling this way"), (4) limited access to emotion regulation strategies perceived as effective (e.g., "When I'm upset, I believe that there is nothing I can do to make myself feel better"), (5) difficulties controlling impulses when experiencing negative emotions (e.g., "When I'm upset, I feel out of control"), and (6) difficulties engaging in goal-directed behaviors when experiencing negative emotions (e.g., "When I'm upset, I have difficulty concentrating"). All questions are self-rated from 1 (almost never) to 5 (almost always). Scores on the subscales range from 5-25 ("clarity," "goals"), from 6-30 ("awareness," "nonacceptance"), and from 7-35 ("impulses," "strategies"). All of the DERS subscales have adequate internal consistency, with alpha reliabilities of .80 or higher for each subscale
(Gratz \& Roemer, 2004). In the clinical group we found alpha reliabilities of .82 or higher for each subscale: .82 for lack of awareness, .88 for lack of clarity, .83 for nonacceptance, .84 for limited strategies, .90 for difficulties controlling impulses, and .82 for difficulties with goals. In the comparison group we found alpha's of .73 for lack of awareness, of .65 for lack of clarity, of .70 for nonacceptance, of .68 for limited strategies, of .72 for difficulties controlling impulses, and of .75 for difficulties goals.

\section{Data Analysis}

Sociodemographic characteristics of the groups were examined using the $t$ test or chi-square test of association, as appropriate. To examine the extent to which the cognitive emotion regulation strategies were reported by the clinical and comparison group, means and standard deviations were calculated. Cohen's $d$ effect sizes were also calculated for all variables. Furthermore, to find out whether an overall multivariate difference existed in the reporting of cognitive strategies between the clinical and comparison group, multivariate analysis of variance (MANOVA) was performed, with and without depression severity as a covariate. Pearson correlations were calculated to examine the relationships between the measurements for emotion regulation and symptoms of depression among the two populations. To identify which of the variables made a unique contribution in distinguishing the two groups, four logistic regression analyses were performed: ${ }^{2}$ with depression severity alone, with cognitive content strategies, with cognitive process strategies, and with depression severity and the significant cognitive strategies of the previous analyses.

2. To avoid multicollinearity problems in multiple regression analyses, special attention will be paid to the mutual correlations among variables that are significantly correlated with the outcome variable. If variables not only appear to show significant correlations with the outcome, but also to show high mutual correlations (.60 and higher), multicollinearity problems can be expected. 
TABLE 1

Group Differences on Measures of Cognitive Content

\begin{tabular}{|c|c|c|c|c|c|}
\hline & Group & $M(S D)$ & $F$ & $F$ cov. & Cohen's $d$ \\
\hline \multirow[t]{2}{*}{ BDI-II } & clinical & $33.78(13.31)$ & $376.12^{* *}$ & & 2.93 \\
\hline & comparison & $5.53(4.29)$ & & & \\
\hline \multirow[t]{2}{*}{ Suicidal Cognitions } & clinical & $61.74(16.70)$ & $373.17^{* *}$ & $200.96^{* *}$ & 2.92 \\
\hline & comparison & $25.46(22.04)$ & & & \\
\hline \multirow[t]{2}{*}{ Self-Concept } & clinical & $15.60 \quad(3.87)$ & $373.08^{* *}$ & $86.80^{* *}$ & 2.91 \\
\hline & comparison & $25.55 \quad(3.02)$ & & & \\
\hline \multirow[t]{2}{*}{ Self-Blame } & clinical & $13.36 \quad(4.01)$ & $72.64^{* *}$ & $19.68^{* *}$ & 1.29 \\
\hline & comparison & $8.74 \quad(3.22)$ & & & \\
\hline \multirow[t]{2}{*}{ Positive Reappraisal } & clinical & $9.98 \quad(3.64)$ & $55.42^{* *}$ & $26.29^{* *}$ & 1.12 \\
\hline & comparison & $13.97 \quad(3.52)$ & & & \\
\hline \multirow[t]{2}{*}{ Catastrophizing } & clinical & $9.21 \quad(3.67)$ & $11.41^{* *}$ & $16.12^{* *}$ & 0.51 \\
\hline & comparison & $7.54 \quad(2.92)$ & & & \\
\hline
\end{tabular}

${ }^{*}$ indicates significance at .05 level; ${ }^{* *}$ indicates significance at .01 level.

BDI-II = Beck Depression Inventory II

\section{RESULTS}

\section{Differences in Demographic Characteristics}

Individuals in the clinical group did not differ from individuals in the comparison group with regard to age $(t=.66, d f=176, p=$ $.51)$, living situation $\left(\chi^{2}=6.23, d f=5, p=\right.$ $.28)$, or educational level $\left(\chi^{2}=15.15, d f=8\right.$, $p=.06)$.

\section{Differences in Reporting of Cognitive Emotion Regulation}

To study the extent to which the cognitive strategies were reported by the clinical group and comparison group, means and standard deviations were calculated for both groups. The results are shown in Table 1 (measures of cognitive content) and Table 2 (measures of cognitive process). In these tables two $F$ values are given: the first is the $F$ value when depression severity is not taken into consideration $(F)$, the second is the $F$ value when depression severity is used as a covariate ( $F$ cov.). Significant differences between the clinical and comparison group were found for all measures of cognitive emotion regulation, even when depression severity was controlled for. Cohen's $d$ are given here as well and they reflect large differences between the two groups (range: $0.53-2.93)$.

\section{Pearson Correlations Between the Measures of Cognitive Content, Cognitive Process, and Depression Severity}

Correlations between subscales ranged between -.008 ("awareness" and "goals") and .81 (suicidal cognitions ${ }^{3}$ and depression) in the clinical group and -0.001 (suicidal cognitions and self-blame) and .66 ("impulses" and

3. Analyses with the separate subscales of the Suicide Cognition Scale (SCS) showed that all its subscales were significantly associated with group membership (history of DSH vs. no history of DSH), with a correlation of .80 for perceived burdensomeness, a correlation of .76 for helplessness, a correlation of .82 for poor distress tolerance, and a correlation of .78 for unlovability. In addition, the subscales had high intercorrelations (ranging from .85 to .92). It is because of these high intercorrelations that we decided to work with the total scale of the SCS. Inclusion of these highly intercorrelated SCS subscales in the regression analyses would lead to problems of multicollinearity. 
TABLE 2

Group Differences on Measures of Cognitive Process

\begin{tabular}{llcccc}
\hline & \multicolumn{1}{c}{ Group } & $M(S D)$ & $F$ & $F$ cov. & Cohen's $d$ \\
\hline Lack awareness & clinical & $20.14(5.04)$ & $24.41^{* *}$ & $7.40^{*}$ & 0.75 \\
& comparison & $16.59(4.49)$ & & & \\
Lack clarity & clinical & $17.34(4.59)$ & $225.09^{* *}$ & $22.00^{* *}$ & 2.28 \\
& comparison & $8.78(2.84)$ & & & \\
Nonacceptance & clinical & $21.10(5.09)$ & $268.38^{* *}$ & $30.67^{* *}$ & 2.44 \\
& comparison & $10.31(3.76)$ & & & \\
Limited strategies & clinical & $23.26(5.84)$ & $265.46^{* *}$ & $75.35^{* *}$ & 2.49 \\
& comparison & $11.57(3.38)$ & & & \\
Difficulties impulses & clinical & $26.17(6.17)$ & $293.73^{* *}$ & $34.67^{* *}$ & 2.59 \\
& comparison & $12.74(4.16)$ & & & \\
Difficulties goals & clinical & $19.74(3.50)$ & $178.936^{* *}$ & $24.492^{* *}$ & 1.99 \\
& comparison & $12.19(4.09)$ & & & \\
\hline
\end{tabular}

${ }^{*}$ indicates significance at .05 level; ${ }^{* *}$ indicates significance at .01 level.

"strategies") in the comparison group (see Table 3 and 4).

\section{Prediction of Clinical and Comparison Group Membership: Logistic \\ Regression Analysis}

When depression severity was entered in the first logistic regression analysis $(\operatorname{method}=$ enter $)$, it yielded a significant model, $\chi^{2}=198.83, d f=1, p<.001$, explaining $67 \%$ of the variance (Cox \& Snell $R^{2}$ ), correctly classifying $95 \%$ of the cases. In the second analysis, the five cognitive content strategies were entered as independent vari- ables $(\operatorname{method}=$ stepwise). The model that resulted was significant, $\chi^{2}=220.39, d f=3$, $p<.001$, explaining $71 \%$ of the variance (Cox \& Snell $R^{2}$ ), correctly classifying $96 \%$ of the cases. Suicidal cognitions, self-concept, and self-blame appeared to have a significant, independent contribution to the prediction of group membership (see Table 5). In the third analysis, the six cognitive process strategies were entered as independent variables (method = stepwise), yielding a significant model too, $\chi^{2}=187.30, d f=3, p<.001$, explaining $66 \%$ of the variance, correctly classifying $99 \%$ of the cases. Lack of clarity, difficulties controlling impulses, and nonacceptance ap-

TABLE 3

Pearson Correlations Between Cognitive Content Strategies and Depression Severity for Clinical Group $(\mathrm{n}=85:$ below diagonal $)$ and Comparison Group Sample $(\mathrm{n}=93$ : above diagonal $)$

\begin{tabular}{lcccccc}
\hline & BDI-II & SCS & $\begin{array}{c}\text { Self- } \\
\text { Concept }\end{array}$ & $\begin{array}{c}\text { Self- } \\
\text { Blame }\end{array}$ & $\begin{array}{c}\text { Catastrophizing } \\
\text { Resitive } \\
\text { Reckpraisal }\end{array}$ \\
Suicide Cognitions Scale & $.81^{* *}$ & - & $-.39^{* *}$ & -.001 & -.03 & -.20 \\
Self-Concept & $-.68^{* *}$ & $-.71^{* *}$ & - & -.11 & -.06 & -.15 \\
Self-Blame & $-.43^{* *}$ & $-.43^{* *}$ & $-.48^{* *}$ & - & $-.40^{* *}$ & $-.28^{* *}$ \\
Catastrophizing & $-.39^{* *}$ & $-.40^{* *}$ & $-.33^{* *}$ & -.16 & $-.42^{* *}$ \\
Positive Reappraisal & $-.473^{* *}$ & $-.49^{* *}$ & $.55^{* *}$ & -.20 & -.18 & -.20 \\
\hline
\end{tabular}

\footnotetext{
${ }^{* *}$ Correlation is significant at the .01 level (2-tailed).Au: Pls confirm
} 
TABLE 4

Pearson Correlations Between Cognitive Process Strategies and Depression Severity for Clinical Sample ( $\mathrm{n}=85$ : below diagonal) and Comparison Group $(\mathrm{n}=93$ : above diagonal)

\begin{tabular}{lccccccc}
\hline & BDI-II & Aware & Clarity & Nonacceptance & Strategies & Impulses & Goals \\
\hline Beck Depression Inventory II & - & -.16 & $.44^{* *}$ & $.31^{* *}$ & $.41^{* *}$ & $.29^{* *}$ & $-.37^{* *}$ \\
Lack of Awareness & $.24^{* *}$ & - & $.40^{* *}$ & .12 & $.28^{* *}$ & .03 & -.20 \\
Lack of Clarity & $.32^{* *}$ & $-.32^{* *}$ & - & $.40^{* *}$ & $.50^{* *}$ & $.42^{* *}$ & $-.32^{* *}$ \\
Nonacceptance & $.46^{* *}$ & -.15 & $.33^{* *}$ & - & $.53^{* *}$ & $.44^{* *}$ & $-.37^{* *}$ \\
Limited Strategies & $.59^{* *}$ & -.10 & $.26^{*}$ & $.52^{* *}$ & - & $.66^{* *}$ & $-.47^{* *}$ \\
Difficulties Impulses & $.47^{* *}$ & -.02 & $.48^{* *}$ & $.40^{* *}$ & $.56^{* *}$ & - & $-.66^{* *}$ \\
Difficulties Goals & $.47^{* *}$ & -.008 & .18 & $.48^{* *}$ & $.56^{* *}$ & $.68^{* *}$ & - \\
\hline
\end{tabular}

${ }^{* *}$ Correlation is significant at the .01 level (2-tailed).

peared to have a significant, independent contribution to the prediction of group membership (see Table 5). A fourth and final logistic regression analysis (method $=$ stepwise) was performed with the significant predictors of the previous steps: depressive symptoms, suicidal cognitions, self-concept, self-blame, lack of clarity, difficulty controlling impulses, and nonacceptance. The results showed that this final model was also significant, $\chi^{2}=226.82, d f=3, p<.001$, explaining $73 \%$ of the variance, correctly classifying $98 \%$ of the cases. Suicidal cognitions and (to a lesser extent) nonacceptance appeared to have a significant, independent contribution to the prediction of group membership over and above depression severity (see Table 5).

\section{DISCUSSION AND CONCLUSIONS}

In the present study we examined the relationship between the use of specific cognitive emotion regulation strategies, depression severity, and DSH. Although previous studies have clearly shown that cognitive strategies are related to DSH, this is the first study to distinguish between specific strategies of cognitive content and process and to include a wide range of cognitive strategies in the same study.

As expected, individuals in the clinical group had significantly higher scores on sui- cidal cognitions, self-blame, catastrophizing, lack of awareness of emotional responses, and nonacceptance of emotional responses. These results are consistent with previous research findings (Donaldson et al., 2000; Garnefski et al., 2001b; Gratz \& Roemer, 2004; Rudd et al., 2001). In addition, they had significantly higher scores on lack of clarity of emotional responses, limited access to emotion regulation strategies, difficulties controlling impulses, and difficulties engaging in goal-directed behaviors. As expected, the comparison group had higher scores on positive self-concept and positive reappraisal, which is in line with previous research showing positive relationships of these strategies with a positive mood (Garnefski et al., 2001a; Grøholt et al., 2005; McGee et al., 2001). It is noteworthy that the group differences remained significant even when depression severity was controlled for.

In addition, we examined the unique contribution of the separate strategies to predict DSH. It was shown that three cognitive content strategies (suicidal cognitions, selfconcept, and self-blame) and three cognitive process strategies (lack of clarity, nonacceptance, and difficulty controlling impulses) independently distinguished the groups. Cognitive content strategies and cognitive process strategies each explained a considerable proportion of the variance, similar to the variance explained by depression severity.

After looking at the separate effect of 


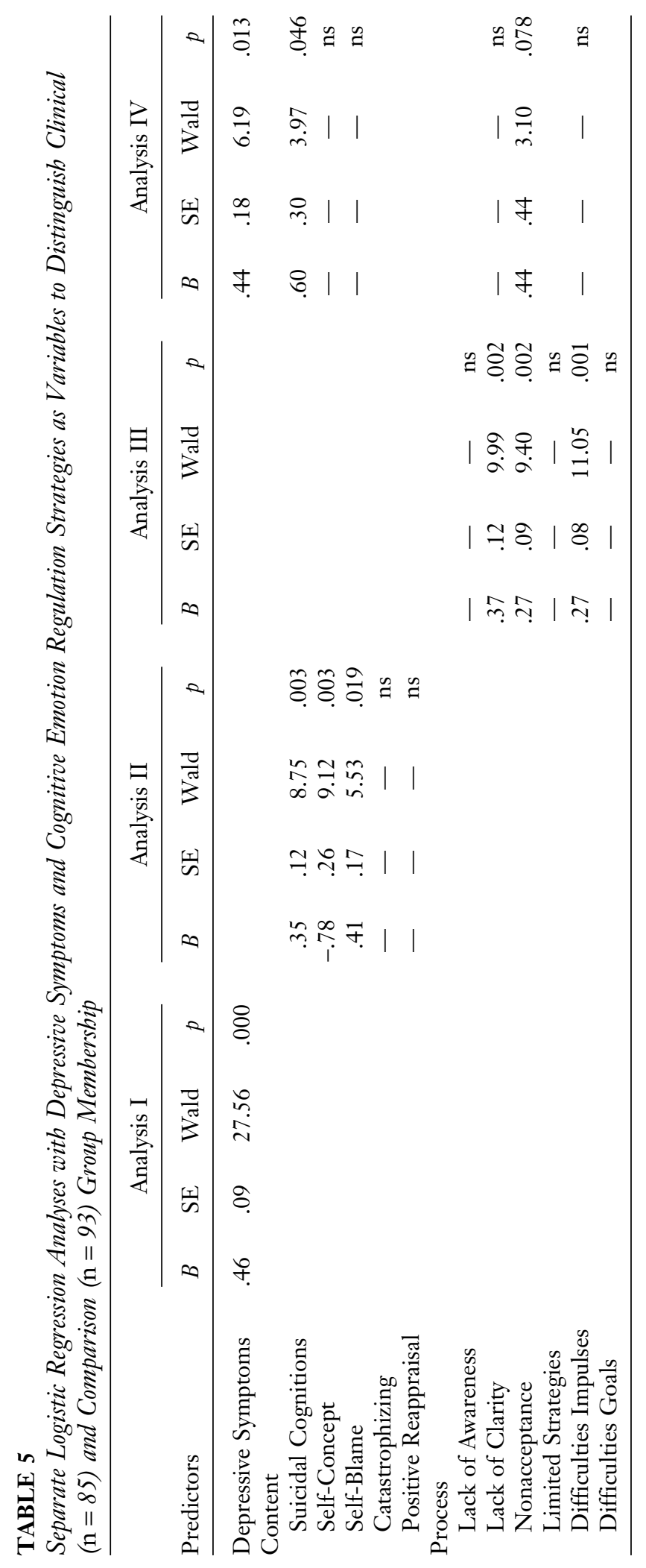


cognitive strategies and depression severity, we looked at their interrelatedness. The table with bivariate correlations showed a high correlation between depression severity and suicidal cognitions in the clinical group. The observation of covariation between depressive symptoms and suicidal cognitions is consistent with the concept of "the suicidal mode" in the theory of Rudd et al. (2001). This theory describes how cognitive and affective systems together may form self-perpetuating cycles of DSH. However, after controlling for depression severity, suicidal cognitions (and to a lesser extent nonacceptance) still appeared to have a significant, independent contribution to the prediction of DSH. This suggests that these cognitions are more than epiphenomena of depression. Alternatively, they seem to be important internal triggers of DSH. This is consistent with research showing that suicidal cognitions, once they have become a feature of depression, can become one of its most persistent features across episodes (Williams et al., 2006) and may become increasingly independent of depression (Witte, Fitzpatrick, Warren, Schatschneider, \& Schmidt, 2006). Since the present study focused on women with a long history of DSH, the strong effect of suicidal cognitions may indicate that these cognitions have become increasingly more accessible with every episode. As a result, even relatively small increases in depressed mood might have gained the capacity to activate suicidal cognitions (Williams, Crane, et al., 2006), increasing vulnerability to recurrences and later episodes of DSH that are more autonomous of external triggers (Post, 1992; Van Heeringen, Hawton, \& Williams, 2000).

DSH also appeared to be associated with nonacceptance of emotions. Nonacceptance of emotions is a key element in a recent theoretical model of DSH, which describes the primary function of DSH as the avoidance of unpleasant emotions (Chapman, Gratz, \& Brown, 2006). According to this model, avoiding emotions through DSH increases the likelihood that an individual will experience a rebound effect consisting of more frequent and more intense emotions.
This is thought to trigger DSH, and the cycle may repeat itself. To help clarify the psychological mechanisms underlying this vicious cycle of DSH, future research might look at data of patients' diaries describing external triggers (e.g., interpersonal conflict), internal triggers (e.g., intense emotions, cognitions of low distress tolerance, and behavioral skill deficits), and avoidance response (DSH) and its consequences (temporary relief). A study among eating disordered patients with DSH shows the utility of assessment of these external and internal triggers of DSH for research and clinical practice (Claes, Vandereycken, \& Vertommen, 2002).

Our findings may have several important clinical implications. For instance, psychotherapeutic interventions aimed at preventing repetition of DSH may best focus on both depressive symptoms and cognitive strategies. There is evidence that cognitive therapy is able to unlink negative cognitions (e.g., thoughts of worthlessness or self-blame) from other symptoms of depression such as low mood (Beevers \& Miller, 2005). The data also imply that it may be beneficial for therapists to target specific suicidal cognitions (e.g., hopelessness, helplessness, unlovability, poor distress tolerance) and other negative self-referent thoughts (e.g., self-blame, low self-esteem). Such interventions are likely to have beneficial effects on depressed mood and may also reduce the probability that suicidal cognitions will become a persistent feature during future depressive episodes (Williams, Crane, et al., 2006). The potential relevance of these interventions is confirmed by a prospective study among depressed patients showing that a decline in depression and in cognitions of hopelessness appeared to reverse the process to DSH (Sokero et al., 2006).

Our findings also show the relevance of cognitive processes in DSH. In particular, lack of clarity of emotional responses, nonacceptance of emotional responses, and difficulty controlling impulses appeared to distinguish between the clinical and comparison group, and may be important targets for intervention. To change these cognitive pro- 
cesses therapy might involve interventions geared toward mindfulness, acceptance, and exposure with response prevention. Indeed, lack of clarity, nonacceptance, and impulse control difficulties are key targets in more recent therapies such as dialectical behavior therapy, mindfulness based cognitive therapy, and acceptance and commitment therapy (Linehan, 1993a,b; Hayes et al., 1999; Williams, Crane, et al., 2006), which include a variety of interventions to enhance acceptance of current experience and to reduce experiential avoidance. For example, mindfulness practice invites individuals who avoid unpleasant emotions to foster an interested, kindly, and accepting stance in relation to these emotions and to the response of avoidance and nonacceptance itself. Through mindfulness practice they may learn to relate differently to cognitive processes that might otherwise fuel suicidal crises (Linehan, 1993; Hayes et al., 1999; Williams et al., 2006). In addition, the experiential avoidance model highlights the utility of teaching behavioral skills for regulating unpleasant emotions (Chapman et al., 2006).

An important question for further research is whether these more recent therapies reduce cognitive reactivity and relapse to a greater extent than traditional cognitive therapy. In addition, even though the importance of cognitive strategies has already been adapted into traditional and more recent cog-

\section{REFERENCES}

Alford, B. A., \& Beck, A. T. (1997). The integrative power of cognitive therapy. New York: Guilford.

Arensman, E., Kerkhof, A.J.F.M.,

Hengeveld, M. W., \& Mulder, J. D. (1995). Medically treated suicide attempts: A four year monitoring study of the epidemiology in The Netherlands. Fournal of Epidemiology and Community Health, 49, 285-289.

Bancroft, J., Hawton, K., Simkin, S., Kingston, B., Cumming, C., \& Whitwell, D. (1979). The reasons people give for taking overdoses: A further inquiry. British Fournal of Medical Psychology, 52, 353-365.

Beck, A. T., Steer, R. A., Ball, R., \& Ranieri, W. F. (1996). Comparison of Beck De- nitive-behavioral treatments for DSH (e.g., Linehan, 1993; Rudd et al., 2001; Williams, Crane, et al., 2006), there is still a need for randomized controlled trials with sufficient power to detect treatment differences (Rudd et al., 2001). Even less is known about specific mechanisms that may underlie treatment effects (e.g., Kazdin \& Nock, 2003). Studies into potential mechanisms of change in cognitive-behavioral therapy of DSH might help to get a better understanding of the factors that maintain it.

A limitation of the present study is that the assessment of cognitive emotion regulation and depression severity was based on self-report only, which may have caused some bias in the form of overreporting or underreporting. Furthermore, due to the cross-sectional nature of the study, causality cannot be inferred and longitudinal studies are needed to understand the order of association between cognitions, depression, and DSH. In addition, it would be interesting to study these cognitive strategies in other populations of DSH patients, such as older women or males. Finally, replication of this study with a comparison group of depressed participants without DSH could help to clarify the specificity of these cognitive strategies for DSH. It is hoped that this study will prompt further research into the influence of cognitive emotion regulation strategies and depression on DSH. pression Inventories IA and II in psychiatric outpatients. Fournal of Personality, 67, 588-597.

Beck, A. T., Steer, R. A., \& Brown, G. K. (1996). Manual for the Beck Depression Inventory II. San Antonio, TX: Psychological Corporation. Beevers, C. G., \& Miller, I. W. (2005). Unlinking negative cognition and symptoms of depression: Evidence of a specific treatment effect for cognitive therapy. Fournal of Consulting and Clinical Psychology, 73, 68-77.

Brown, S. L., \& Vinokur, A. D. (2003). The interplay among risk factors for suicidal ideation and suicide: The role of depression, poor health, and loved ones' messages of support and criticism. American Fournal of Community Psychology, 32, 131-141. 
Chapman, A. L., Gratz, K. L., \& Brown, M. Z. (2006). Solving the puzzle of deliberate selfharm: The experiential avoidance model. Behaviour Research and Therapy, 44, 371-394.

Claes, L., Vandereycken, W., \& VertomMEN, H. (2002). Therapy-related assessment of self-harming behaviors in eating disordered patients: A case illustration. Eating Disorders: Treatment and Prevention, 10, 269-279.

Donaldson, D., Spirito, A., \& Farnett, E. (2000). The role of perfectionism and depressive cognitions in understanding the hopelessness experienced by adolescent suicide attempters. Behavioral Science, 31, 99-111.

D'Zurilla, T. J., Chang, E. C., Nottingham, E. J., \& Faccini, L. (1998). Social problemsolving deficits and hopelessness, depression, and suicidal risk in college students and psychiatric inpatients. Fournal of Clinical Psychology, 54, 10911107.

Fazaa, N., \& Page, S. (2003). Dependency and self-criticism as predictors of suicidal behavior. Suicide and Life-Threatening Behavior, 33, 172185.

Garnefski, N., Kraaij, V., \& Spinhoven, P. (2001a). Negative life events, cognitive emotion regulation and emotional problems. Personality and Individual Differences, 30, 1311-1327.

Garnefski, N., KraaiJ, V., \& Spinhoven, P. (2001b). De relatie tussen cognitieve copingstrategieën en symptomen van depressie, angst en suïcidaliteit. Gedrag en Gezondheid, 29, 148-158.

Garnefski, N., Kraaij, V., \& Spinhoven, Pн. (2002). Manual for the use of the cognitive emotion regulation questionnaire. Leiderdorp, The Netherlands: DATEC.

Garnefski, N., Teerds, J., KraAiJ, V., Legerstee, J., \& van den Kommer, T. (2004). Cognitive emotion regulation strategies and depressive symptoms: Differences between males and females. Personality and Individual Differences, 36, 267-276.

Glanz, L. M., Haas, G. L., \& Sweeney, J. A. (1995). Assessment of hopelessness in suicidal patients. Clinical Psychology Review, 15, 49-64.

Gratz, K. L., \& Roemer, L. (2004). Multidimensional assessment of emotion regulation and dysregulation: Development, factor structure, and initial validation of the difficulties in emotion regulation scale. Fournal of Psychopathology and Behavioural Assessment, 26, 41-54.

Grøholt, B., Ekeberg, Ø., Wichtenstrøm, L., \& Haldorsen, T. (2005). Suicidal and nonsuicidal adolescents: Different factors contribute to self-esteem. Suicide and Life-Threatening Behavior, 35, 525-535.

Hayes, S. C., Follette, V. M., \& LineHAN, M. M. (EDs.). (2004). Mindfulness and acceptance: Expanding the cognitive-behavioral tradition. New York: Guilford.
Hayes, S. C., Strosahl, K., \& Wilson, K. G. (1999). Acceptance and commitment therapy: An experimental approach to behavior change. New York: Guilford .

Joiner., T. E., Rudd, M. D., \& Lester, D. (2002). Perceived burdensomeness and suicidality: Two studies on the suicide notes of those attempting and those completing suicide. Fournal of Social and Clinical Psychology, 21, 531-545.

Hawton, K., Zahl, D., \& Weatherall, R. (2003). Suicide following deliberate self-harm: Long-term follow-up patients who presented to a general hospital. British Fournal of Psychiatry, 182, 537-542.

Kazdin, A. E., \& Nock, M. K. (2003). Delineating mechanisms of change in child and adolescent therapy: Methodological issues and research recommendations. Fournal of Child Psychology \& Psychiatry, 44, 1116-1129.

Kendall, P. C., \& Ingram, R. E. (1989). Cognitive-behavioral perspectives: Theory and research on depression and anxiety. In P. C. Kendall \& D. Watson (Eds.), Anxiety and depression: Distinctive and overlapping features. New York: Guilford.

Linehan, M. M. (1993a). Cognitive-behavioral treatment of borderline personality disorder. New York: Guilford.

Linehan, M. M. (1993b). Skills training manual for treating borderline personality disorder. New York: Guilford.

McGee, R., Williams, S., \& Nada-Raja, S. (2001). Low self-esteem and hopelessness in childhood and suicidal ideation in early adulthood. Fournal of Abnormal Child Psychology, 29, 281-291.

Nolen-Hoeksema, S. (1991). Responses to depression and their effects on the duration of depressive episodes. Fournal of Abnormal Psychology, 100, 569-582.

Nolen-Hoeksema, S. (2002). The role of rumination in depressive disorders and mixed anxiety/depressive symptoms. Fournal of Abnormal Psychology, 109, 504-511.

Post, R. M. (1992). Transduction of psychological stress into the neurobiology of recurrent affective disorder. American Fournal of Psychology, 149, 999-1009.

Robson, P. J. (1989). Development of a new self-report questionnaire to measure self-esteem. Psychological Medicine, 19, 513-518.

Rudd, M. D. (2004). Cognitive therapy for suicidality: An integrative, comprehensive, and practical approach to conceptualization. Fournal of Contemporary Psychotherapy, 34, 59-72.

Rudd, M. D., Joiner, T., \& RaJab, M. H. (2001). Treating suicidal behavior: An effective, timelimited approach. New York: Guilford.

Slee, N., Garnefski, N., van der Leeden, R., Arensman, E., \& Spinhoven, Ph. (2008). Outcomes of a randomized controlled trial of a cogni- 
tive behavioural intervention for deliberate selfharm patients. British Fournal of Psychiatry, 192, 202-211.

Smith, J. M., Aloy, L. B., \& Abramson, L. Y. (2006). Cognitive vulnerability to depression, rumination, hopelessness, and suicidal ideation: Multiple pathways to self-injurious thinking. Suicide and Life-Threatening Behavior, 36, 443-454.

Sokero, P., Eerola, M., Rytsälä, H., Melartin, T., Leskelä, U., Lestelä-Mielonen, P., ET AL. (2006). Decline in suicidal ideation among patients with MDD is preceded by decline in depression and hopelessness. Fournal of Affective Disorders, 95, 95-102.

van Heeringen, K., Hawton, K., \& WilLIAMs, J.M.G. (2000). Pathways to suicide: An integrative approach. In $\mathrm{K}$. Hawton and $\mathrm{K}$. van Heeringen (Ed.), The international bandbook of suicide and attempted suicide (pp. 223-234). Chichester, England: Wiley.

Watkins, E. R., \& Teasdale, J. D. (2004). Adaptive and maladaptive self-focus in depression. Fournal of Affective Disorders, 82, 1-8.

Wells, A. (2002). GAD, metacognition and mindfulness: An information processing analysis. Clinical Psychology: Science and Practice, 9, 95100.

Wells, A., \& Matthews, G. (1994). At- tention and emotion: A clinical perspective. Hove, UK: Lawrence Erlbaum.

Williams, J.M.G., Barnhofer, T., Crane, C., \& Beck, A. T. (2005). Problem solving deteriorates following mood challenge in formerly depressed patients with a history of suicidal ideation. Fournal of Abnormal Psychology, 114, 421-431.

Williams, J.M.G., Crane, C., Barnhofer, T., Van der Does, A.J.W., \& Segal, Z. V. (2006). Recurrence of suicidal ideation across depressive episodes. Fournal of Affective Disorders, 91, 189194.

Williams, J.M.G., Duggan, D. S., Crane, C., \& Fennell, M.J.V. (2006). Mindfulness-based cognitive therapy for prevention of recurrence of suicidal behavior. Fournal of Clinical Psychology, 62, 201-210.

Witte, T. K., Fitzpatrick, K. K., Warren, K. L., Schatschneider, C., \& Schmidt, N. B. (2006). Naturalistic evaluation of suicidal ideation: Variability and relation to attempt status. Behaviour Research and Therapy, 44, 1029-1040.

Young, J. E., Klosko, J. S., \& Weishaar., M. E. (2003). Schema therapy: A practitioner's guide. New York: Guilford.

Manuscript Received: December 26, 2006 Revision Accepted: August 7, 2007 